\title{
Autores ajuglarados y mester de clerecía. Filiación retórica y temática entre el Cantar de mio Cid y el Libro de Alexandre
}

Palabras clave: Cantar de mio Cid, Libro de Alexandre, Influencia, Retórica, Hábitos juglarescos

A Francisco Márquez Villanueva

En Poesía juglaresca y juglares, Ramón Menéndez Pidal propone una relación de influencia entre la épica castellana y los textos de los primeros clérigos de la cuaderna vía ${ }^{1}$. Según el gran erudito, la poesía juglaresca sirvió como modelo para aquellos clérigos que se iniciaban en la escritura de la lengua vulgar. Entre las brillantes observaciones que dedica al creador del Alexandre destaca aquella en la que lo llama un autor «ajuglarado» (Menéndez Pidal, 1991: 359)². En efecto, tanto las primeras como las últimas estrofas del texto contienen reminiscencias juglarescas:

Señores, si queredes mi serviçio prender,

querríavos de grado servir de mi mester;

deve de lo que sabe omne largo seer,

si non, podrié en culpa e en riebto caer.

1 En cambio, Marcelino Menéndez Pelayo opina que el mester de clerecía «marca su distinción respecto del arte rudo de los juglares» (1944-1945: 51). Este punto de vista ha sido cuestionado por varios críticos, en particular por Raymond S. Willis (1957: 212-224) y Francisco López Estrada (1978: 165-174).

2 Es más difícil coincidir con la idea de Menéndez Pidal según la cual los poemas de Berceo, el Alexandre o el Fernán González estuviesen destinados «a la recitación pública» (1991: 360). En el caso del Libro de Alexandre la temática sugiere a otros clérigos como posibles lectores. 
Mester traigo fermoso, non es de joglaría, mester es sin pecado, ca es de clerezía fablar curso rimado por la cuaderna vía, a sílabas contadas, ca es grant maestría.

Qui oir lo quisiere, a todo mi creer, avrá de mí solaz, en cabo grant plazer, aprendrá buenas gestas que sepa retraer, averlo an por ello muchos a connoçer. ${ }^{3}$

«A pesar de la superioridad de que se jacta, el clérigo ofrece su mester u oficio a los oyentes, como cualquier juglar, y quiere proporcionar al público el 'solaz' propio del oficio juglaresco» (1991: 358), apunta Menéndez Pidal sobre estas estrofas iniciales. De igual forma, el anónimo autor del Alexandre acepta varios usos juglarescos al final del poema:

Quiérome vos con tanto, señores, espedir;

gradéscovoslo mucho quem quisiestes oïr;

si falleçí en algo, devedes me parçir,

só de poca çïençia, devedes me sofrir.

Pero pedir vos quiero çerca de la finada,

-quiero de mi servicio de vos prender soldada-:

dezid el Paternoster por mí una vegada;

a mí faredes pro, vos non perdredes nada. (2673-2674)

El autor se dirige a un público que aparentemente lo está escuchando y del cual solicita una recompensa. Los juglares acostumbraban a pedir dinero o vino; nuestro autor se satisface con un padrenuestro.

3 Estrofas 1-3. Utilizo la edición de J. Cañas (1998); en adelante, sólo se indicará el número de estrofa entre paréntesis o si se citan versos sueltos se antepondrá el número de estrofa, con el respectivo verso señalado por una letra. 


\section{Punto de partida: retórica y léxico comunes}

Uno de los primeros, después de Menéndez Pidal, en estudiar la ascendiente del Cid sobre el Alexandre fue Ian Michael quien ve en la promesa de Alejandro de casar a las hijas de Darío honradamente (estrofas 1784-1785) una clara reminiscencia del deseo del campeador por casar bien a sus hijas (Michael, 1970: 129)4. A él le han seguido Colin Smith y Dana A. Nelson. El primero sostiene que, si bien es cierto que existían otros cantares además del Cid que hayan podido influir en los autores de la cuaderna vía, hay «rasgos distintivos de la retórica del Poema de mio Cid que al repetirse en textos posteriores se pueden atribuir con cierta confianza a la influencia directa de éste» (Smith, 1980: 423). El crítico agrupa los elementos distintivos en ocho apartados: 1. Epiteto épico: a) de persona y b) de lugar, 2. Binomios, 3. O dizen..., 4. Ablativo absoluto, 5. Admiratio, 6. Fórmula narrativa, 7. Burgos la casa y 8. Comer el pan de uno.

A su vez Nelson, en su empeño de atribuir la autoría del Alexandre a Gonzalo de Berceo -cuestión debatible-, ubica llamativas coincidencias que apuntan hacia una muy probable influencia del Cantar en el Alexandre. En resumen, los estudios de Menéndez Pidal, Michael, Smith y Nelson sugieren una red de reminiscencias y ecos temáticos entre el Cantar de mio Cid y el Libro de Alexandre. Ahora bien, hasta el día de hoy no existe un catálogo extenso de concordancias, que permita corroborar las sospechas de los eruditos de marras. En las páginas que siguen se ofrece no sólo dicho catálogo, sino también un análisis pormenorizado de las correspondencias más sobresalientes. A través de los elementos retóricos comunes, de imágenes y léxico compartidos y del empleo semejante de la voz narrativa, se establece de manera definitiva la relación de dependencia que existe del Alexandre para con el Poema de mio Cid.

\subsection{Binomios}

Según se ha dicho, Smith divide los rasgos distintivos de la retórica del Cid, que se repiten de manera clara en textos posteriores, en ocho apartados. Aunque el estudioso concede que los binomios son parte de la retórica común de la época, no descarta la posibilidad de «que alguna expresión muy típica del Mio Cid haya pasado por vía directa a los demás poetas, como es la pareja moros $e$ cristianos en sus diversas aplicaciones» (Smith, 1980: 423). En efecto, en el Cid se repite en varias ocasiones dicho binomio:

4 En un trabajo previo Michael abordó la cuestión del ajuglaramiento del autor del Alexandre a partir de un estudio sobre el epíteto épico (1961: 32-41). 
968 entre moros e cristianos gentes se le allegan grandes

988 de moros e de cristianos gentes trae sobejanas

2498 moros e cristianos de mí han grant pavor ${ }^{5}$

Por su lado, en el Libro de Alexandre sólo aparece una vez: «non tragó peor hueso nin moro nin cristiano» (1371d). Como en el Cantar, el binomio utilizado negativamente quiere decir nadie. Sin embargo, el Alexandre introduce dos binomios similares y sus variaciones, que no figuran en el Cid. El primero es moros e judios y el segundo, judios e paganos:

$87 \mathrm{~d} \quad$ non treguava en el siglo a judío nin moro

$2332 \mathrm{~b} \quad$ ca moros e judios temién la su espada

2544c nunca tan ricas vío nin judío nin moro

$1195 \mathrm{~d} \quad$ ca sobre nos son estos, judios e paganos

El autor del Alexandre se desvía del Cid y produce dos binomios originales. Esto denota que las reminiscencias no tienen que ser una copia al carbón, sino que pueden manifestarse en forma de sinónimo, antónimo o variación.

Otro binomio común es oro e plata y sus variaciones a partir de una preposición que le antecede («con», «de», «entre»). Así en el Cid:

$81 \quad$ Espeso é el oro e toda la plata

310 por oro nin por plata non podrié escapar

473 gañó a Castejón e el oro e la plata

799 traen oro e plata que non saben recabdo

$820-$ Evades aquí oro e plata

1214 el oro e la plata ¿quién vos lo podrié contar?

1737 entre oro e plata fallaron tres mill marcos

1970 escudos boclados con oro e con plata

El Libro de Alexandre emplea el binomio casi el mismo número de veces:

87 b ya partié a quarterones la plata e el oro

$662 \mathrm{~b} \quad$ que por oro nin plata non sería comprado

5 Utilizo la edición de A. Montaner (1998). En adelante, antepongo a las citas del Cid el número del verso. 
$967 \mathrm{a}$ de oro e de plata vienen todos armados

1639d de oro e de plata quanto levar pudiessen

$1892 \mathrm{~b}$ trayén oro e plata a fiera abondançia

2667 b por oro nin por plata non lo podrié comprar

El Cid utiliza el binomio en los dos hemistiquios y le antepone una mayor variedad de preposiciones. El Alexandre, por otra parte, sólo una vez lo usa en el segundo hemistiquio e invierte su orden, al mencionar primero la plata y, después, el oro. Asimismo llaman poderosamente la atención dos pares de versos por su similitud: Cid 310 y Alexandre $2667 \mathrm{~b}$, Cid 799 y Alexandre $1892 \mathrm{~b}$. En ambos casos estamos ante una repetición de contenido y forma.

Otro binomio con características similares es los días y las noches. En el Alexandre su empleo se reduce al primer hemistiquio, mientras que en el Cantar se encuentra en ambos:

Alexandre:

$32 \mathrm{~d} \quad$ essa nocb nin ese día nunca aviá folgado

$634 \mathrm{a}$ los días e las noches non les davan vagar

806c vinién noches e días quajadas las carreras

$1110 \mathrm{~b}$ de noche nin de día non les demos vagar

1733a de noche nin de día vagar nunca se dieron

1986b de día nin de noche non quedó de andar

Cid:

434 andidieron de noch, que vagar non se dar

562 que de día nin de nocb non les diessen arrebata

824 que ruegen por mí las noches e los días

1823 andan los días e las noches, que vagar non se dan

2002 que non se abriessen de día nin de noch

Nuevamente se manifiesta en dos pares de versos una analogía inquietante: Alexandre 634a y Cid 1823, Alexandre 1110 b y Cid 434. 
El último binomio es, a diferencia de los precedentes, más común en el Alexandre que en el Cid. Se trata de la familia formulística en torno a pan e vino. En el Cantar sólo aparece en dos ocasiones:

66

a mio Cid e a los suyos abástales de pan e de vino

1025 -Comed, conde, d'este pan e beved d'este vino

No obstante, en el Libro de Alexandre hay, por lo menos, cinco versos en los que figura el binomio ya en su forma original, ya como variación:

109b y fuera con pan cocho e con vino criado

$282 \mathrm{c}$ de panes e de vinos non ha tierra calaña

1494a de panes e de vinos es la villa abondada

1793a quáles tierras son buenas de panes e de vinos

2477 b rico de buen esfuerço pobre de pan e vino

\subsection{Fraseología}

Las frases hechas son un elemento fundamental para confirmar la fuerte relación entre estas dos obras. Cabe señalar que se ha optado por aislar sólo tres frases hechas a guisa de ejemplo, aunque debe considerarse que este apartado podría crecer ampliamente a partir de la inclusión de varios sintagmas que se analizarán en otros apartados. Aver monedado o averes monedados, o sea, dinero en metálico, conforma una frase hecha importante:

Alexandre:

$242 \mathrm{~b}$ dióle quanto él quiso de aver monedado

988a nin poder nin esfuerço nin aver monedado

1286d que non seré más rico por aver monedado

Cid:

126 non duerme sin sospecha qui aver trae monedado

1217 en el aver monedado treinta mill marcos le caen

172 grádanse Rachel e Vidas con averes monedados

2257 non fueron en cuenta los averes monedados

$3236-$ Averes monedados non tenemos nós - 
En el Cantar se emplea el sintagma en ambos hemistiquios, mientras que en el Alexandre sólo aparece en el segundo y en singular. Igualmente, los dos textos muestran un cierto desprecio por el dinero (Cid 126 y Alexandre 1286d). La segunda frase hecha es a manos prender o tomar:

$1020 \mathrm{c}$ cuidaron sines dubda prendérselo a manos

974 así viene esforçado el conde que a manos se le cuidó tomar

Y la tercera, buen galardón:

1075c diole el su cavallo, -idél Dios buen gualardón!

$2126 \quad ¡$ ¡Dios que está en el cielo dévos dent buen galardón!

2855 ¡Afé Dios de los cielos, que vos dé dent buen galardón!

3416 Essora dixo el rey: -¡Dios vos dé den buen galardón!

\section{El narrador y los hábitos juglarescos}

Cuando Menéndez Pidal habla de un autor «ajuglarado» en relación al creador del Alexandre, no sólo se refiere a las primeras y últimas estrofas del poema, sino también a otros hábitos juglarescos, como el «interés de actualidad presente que a veces [el autor del Alexandre] da a su relato, tomando partido en los sucesos» (Menéndez Pidal, 1991: 359). El erudito recuerda, en el mismo sentido, que cuando Alejandro va a Babilonia el poeta se encara con él ${ }^{6}$. En efecto, en ambas situaciones el autor del Alexandre revela su voz íntima con respecto a los acontecimientos, lo cual suele identificarse como una característica más propia del narrador de los cantares de gesta y, particularmente, del narrador del Cid. Sobre el comportamiento de la voz narradora en el Cid, comenta Montaner:

Pese a lo que quizá podría esperarse de un narrador que se encuentra en un plano distinto del de lo narrado, aquél [el del Cid] se materializa a veces ante los receptores. Como señala Segre, «la personalización del narrador se realiza entre dos polaridades: insistencia sobre el tú, esto es, las alocuciones al destinatario, o bien, sobre el yo, sobre la individualidad del narrador, que se impone también como juez o intérprete de los hechos y comportamientos». La voz narradora del Cantar emplea ambos procedimientos, es decir, la apelación al

6 Estrofa 2530. 
auditorio, en segunda persona, y la referencia a sí mismo, en primera persona. (Montaner, 1998: 57)

\subsection{Personalización del narrador}

Respecto a las referencias del narrador a sí mismo, Montaner agrega que éstas no sólo se basan en la primera persona, sino también en «las exclamaciones que muestran la sintonía con sus personajes» (Montaner, 1998: 58). Esto significa que el narrador declara su simpatía o antipatía hacia uno o varios personajes mediante expresiones de admiración o desprecio. Se divide la insistencia sobre el «yo» en cuatro grupos: a) primera persona del singular, b) primera persona del plural, c) admiración y d) desprecio. En los primeros versos del Alexandre prolifera la primera persona:

$1 \mathrm{a}$

$1 \mathrm{~b}$

$2 \mathrm{a}$

$3 \mathrm{a}$

$3 \mathrm{~b}$

$4 \mathrm{a}$

$4 \mathrm{~b}$

$5 \mathrm{a}$

$11 \mathrm{~d}$ señores, si queredes mi serviçio prender

querríavos de grado servir de mi mester

mester traigo fermoso, non es de joglaría

qui oir lo quisiere, a todo mi creer

avrá de mí solaz, en cabo grant plazer

non vos quiero grant prólog nin grandes nuevas fer,

luego a la materia me vos quier' acoger

quiero leer un livro d'un rey noble, pagano

-en escripto yaz' esto, sepades, non vos miento

Ahora bien, la presencia del «yo» se extiende a lo largo de todo el texto7 ${ }^{7}$ Otra de las particularidades del Alexandre es la aparición del «yo» en la primera persona del plural:

2066a avremos - non vos pese-, la cosa destajar

2119b maguer non la podamos dignamente contar

2119c porque mucho queramos la verdat alabar

7 Para no cansar de manera innecesaria al lector, se ofrecen a continuación sólo los números de los versos donde emerge la subjetividad del narrador: 90d, 91d, 111a, 905b, 961b, 1178d, 1417d, 1494c, 1505a, 1532d, 1754a, 1862a, 1971a, 1992a, 2126d, 2157d, 2305d, 2334b, 2360a, 2381a, 2390a, 2391a, 2397a, 2421a, 2465b, 2522c, 2539bc, 2545a, 2548a, 2595a, 2663bcd y las estrofas 2673 y 2674 completas. 
2164b -non leemos su nombre, non vos lo sé dezir-

2469d maguer que non de todas, de algunas digamos ${ }^{8}$

Como en el Cid, el autor del Libro de Alexandre se sirve de exclamaciones que muestran su simpatía por algún personaje o por un grupo:

96ob non se podién llegar, ¡tant' eran desmayadas!

975b sól no lo entendién ¡tant'eran corajados!

1018b -cavallero de preçio, si l'oyestes contar-9

La otra cara de la moneda es cuando el autor no se muestra benévolo hacia sus personajes y los juzga negativamente e, incluso, pide a gritos su condenación:

$1115 \mathrm{~d} \quad$-por fe, a mí nom pesa, ca bien lo mereçieron-

1372d - por verdat vos dezir, de tal colpe me pago-

1648d -devrié quebrar la tierra con tan falsos varones-

1714d -de Dios sean cofondidos atales serviçiales-

2616d -jtambién podrién al malo darle grant cuchillada!-

La siguiente estrofa es de singular interés:

¡Maldito sea el cuerpo que atal cosa faze!

¡Maldito sea el alma que en tal cuerpo yaze!

¡Maldito sea cuerpo que tal cosa le plaze!

¡Dios lo eche en laço que nunca se deslaçe! (2618)

Alejandro acaba de ser envenenado y el autor padece un desgarramiento interno, además de un profundo dolor. Esta situación se verbaliza en la maldición que lanza sobre los traidores. Según se colige, la voz narrativa del Alexandre no siempre es neutral, sino que tiende a exteriorizar sus preferencias al grado de influir en el estado de ánimo del lector. Una voz narrativa con rasgos de intimidad no es, generalmente, asociada al Alexandre, pero, ésta debe ser identificada como uno de los elementos más representativos que contribuye a su "ajuglaramiento".

8 Versos similares: 2423a, 2470a, 2471a.

9 Versos con características afines: 92b, 204d, 777d, 902b, 904b, 1020b, 1075c, 1083 d, 1437c, $1592 \mathrm{~d}, 1681 \mathrm{~d}$ y $1683 \mathrm{~d}$. 


\subsection{Diálogo con el narratario}

Precisa enumerar, ahora, aquellos ejemplos en los que el narrador insiste sobre el «tú»:

11 -en escripto yaz' esto, sepades, non vos miento-

$1360 \mathrm{c}$ sabet, non semejavan fijos de sendas madres

1715a sabet, non lo dexaron en la tienda estar

49a repuso el infant, -nunca viestes mejor-

1b querríavos de grado servir de mi mester

4a non vos quiero grant prólogo nin grandes nuevas fer

1957a quiérovos brement dezir el brevïario

2539b quiérovos de la obra de la tienda dezir

$1 \mathrm{a}$

señores, si queredes mi serviçio prender

2424a tant' avemos, señores, la razón alongada

$2670 a$ señores, quien quisiere su alma bien salvar

2673a quiérome vos con tanto, señores, espedir

719a Éctor murió, amigos, com' avedes oído

2398a el diablo, amigos, que nunca pued dormir

1505 a creo que bien podiestes alguna vez oïr

$1532 \mathrm{~d}$-temo dirá alguno: "Ya, varón, que tú mientes"-

2066a avremos -non vos pese-, la cosa destajar

2164 -non leemos su nombre, non vos lo sé dezir-

$2360 a$ un enxemplo vos quiero en esto adozir

2397a si un poco quisieredes saber mi entender

2423a que mucho vos queramos del infierno dezir 
Es evidente que el autor del Alexandre tiene en cuenta a un interlocutor en varios momentos de la redacción. Sabet, señores, amigos son locuciones que están explícitamente dirigidas a un receptor. Aunado a esto hay que señalar que el diálogo entre narrador y narratario persiste a lo largo de todo el poema y no sólo al final o al inicio, como la crítica ha venido tradicionalmente sosteniendo; esta peculiaridad remite de nueva cuenta a la voz narradora de la épica castellana y, en particular, al Poema de mio Cid.

\section{Temas}

A continuación se agrupan en seis subapartados temas comunes a ambas obras y que, por su frecuente aparición, ameritan estudiarse con detenimiento.

\subsection{El botín y su reparto}

Uno de los núcleos temáticos más ambiciosos es la obtención de las ganancias y su justa distribución ${ }^{10}$. El reparto del botín se presenta en el Alexandre desde el discurso de Aristóteles y se extiende a lo largo de todo el poema:

$62 \mathrm{~b} \quad$ non te prenda cobdiçia de condesar aver;

$62 \mathrm{c}$ quanto que Dios te diere pártelo volenter

$82 \mathrm{~b} \quad$ non te prenda cobdiçia a ti de prender nada;

$82 \mathrm{c}$ parte bien la ganançia a la tu gent lazrada

$974 \mathrm{c}$ de toda la ganançia me vos quiero quitar

1455 b partió bien la ganançia a toda derechura

Al igual que Alejandro, el Cid es consciente de que el botín representa una de las grandes motivaciones de sus hombres para permanecer a su lado y pelear. Por esta razón, se esmera en vigilar su justa distribución:

510 mandó partir tod aquesta ganancia

804 dio a partir estos dineros e estos averes largos

Y versos 2484- 2486:

10 Adviértase que el tema del dinero en el Alexandre es muy distinto al de la tradición tan «medievalizada» del Alejandro ultrapirenaico. En casi todas las gestas francesas, lo mismo que en obras de corte eclesiástico, el tema del dinero y de las ganancias no figura si no es como objeto de condenación o de sátira. En cambio, en el Alexandre su tratamiento es mucho más complejo. 
Mandó mio Cid, el que en buen ora nasco,

d'esta batalla que han arrancado

que todos prisiessen so derecho contado

Es interesante que las ganancias sean consideradas una recompensa de Dios a sus esfuerzos. Por ejemplo en el Alexandre:

1079d e coger la ganançia que Dios les avié dada

1080b más averes trobaron que a Dios nunca pidieron

Y en el Cid:

1334 grandes son las ganancias que l' dio el Criador

2316 que les crece la ganancia grado al Criador

También los dos poemas enfatizan el aspecto formidable de las ganancias:

1344a traen grandes riquezas, thesoros sobejanos

$1455 \mathrm{~d}$ dizién que era grant ganançia sin mesura

1892a como avién las gentes fechas fiera ganançia

110 grandes averes priso e mucho sobejanos

$480 \quad$ tanto traen las grandes ganancias

944 todos son alegres, ganancias traen grandes

1016 plogo a mio Cid ca grandes son las ganancias

1334 grandes son las ganancias que l' dio el Criador

Mientras que en el Alexandre se utilizan tres distintas frases para aludir a lo extraordinario de las ganancias, en el Cid ocurre una repetición literal de la frase grandes ganancias.

El enriquecimiento de los pobres, la ordenación de las ganancias y su transporte son otros elementos compartidos. En varias ocasiones, el Cid se ve obligado a hacer promesas para atraer más hombres a sus huestes. En una ocasión sostiene que sacará a los pobres de su escasez material y los convertirá en ricos, lo que, en efecto, cumple: «A cavalleros e a peones fechos los ha ricos, / en todos los sos non fallariedes un mesquino» (848-849). En comparación, el Libro de Alexandre reza: 
972b a los que fueren pobres sacaré de pobreza

1344d nunca avrán pobreza los que salieren sanos

Por otra parte, los dos poemas recurren a la misma expresión (en buen recabdo) para describir cómo se ordenan y se ponen en seguridad las ganancias:

1166a puso en buen recabdo lo que avié ganado

Y el Cantar:

1255 afevos todo aquesto puesto en buen recabdo

1738 de las otras ganancias non avía recabdo

Finalmente, hay una formulación muy similar para la descripción del transporte de las ganancias. Los primeros dos versos de la estrofa 926 del Alexandre dicen: «traes grandes averes en uno ajuntados / azémilas e carros e camellos cargados». De manera casi idéntica, el verso 2705 del Cid suena: «mandaron cargar las azémilas con grandes averes a nombre». Se trata de una profunda reminiscencia-casi una calca- en los niveles de forma y contenido.

\subsection{Sueños y héroes}

Los dos héroes tienen un sueño revelador donde un ángel les profetiza sus futuros éxitos y conquistas. Para calmar a sus hombres que no entienden por qué perdonó la vida a los habitantes de Jerusalén, Alejandro les explica que a la muerte de su padre Filipo, tuvo un sueño que recordó en el momento de ser recibido por el obispo de aquella ciudad:

Estrofa 1149:

Estava en mi cámara en mi lecho yaziendo,

de las cosas del regno yazía comidiendo;

fue con la grant anxía el sueño trasponiendo,

yazía en grant cueita, grant lazerio sufriendo.

Estrofa 1153:

Paróseme de suso un omne revestido,

porque omne lo llamo, téngome por fallido, 
creo que era ángel del çielo deçendido, ca non avié tal cara ningunt omne naçido.

Alejandro cree reconocer en el obispo de Jerusalén la misma cara y el mismo vestido del hombre de su sueño y, por esta razón, no ejerce violencia contra ese pueblo. Todo lector del Cantar recuerda la escena en que el Cid tiene un sueño, donde también se le aparece un ángel (versos 404-409):

Ý se echava mio Cid después que cenado fue, un sueño l' priso dulce, tan bien se adurmió;

el ángel Gabriel a él vino en sueño:

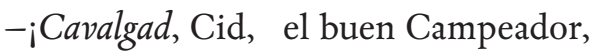

ca nuncua en tan buen punto cavalgó varón!

Mientra que visquiéredes, bien se fará lo to.-

Las reminiscencias son evidentes: un ángel, o alguien que semeja un ángel, se les aparece a ambos protagonistas en un sueño. Al Cid le aconseja que cabalgue augurándole el mayor de los éxitos, y a Alejandro lo alienta a alejarse de Europa y le promete que conquistará el mundo:

Entiende, Alexandre, que te quiero fablar;

salte de Eüropa, vete a ultramar,

avrás todos los regnos del mundo a ganar,

nunca fallarás omne quet pueda contrastar. (1157)

Pero la similitud no se agota aquí. Después de escuchar la profecía, los dos héroes recuerdan a Dios. En el Cantar se lee: «Cuando despertó el Cid, la cara se santigó, / sinava la cara, a Dios se acomendó» (410-411). Y Alejandro, en la estrofa 1162, comparte con sus hombres su sentir:

Bien sepades, amigos, que aquel mandadero

mensaje fue de Dios por fer a mí çertero;

a mi Esse me guía, non otro agorero,

vos lo veredes todos que será verdadero.

Como se observa, prevalecen en el sueño de Alejandro fuertes ecos temáticos del sueño del Campeador. 
Otra resonancia del Cantar en el Alexandre tiene su origen en los versos 1704-1705. Por la mañana del día en que el Cid se ha propuesto romper el cerco de Valencia, el obispo don Jerónimo dice una misa y concede una absolución general:

- El que aquí muriere lidiando de cara,

préndol' yo los pecados e Dios le abrá el alma (1704-1705).

Durante la batalla de Taxila contra el rey Poro, el narrador del Alexandre afirma que todos se muestran extremadamente valientes «como si les echassen perdón de sus pecados» (2049d). A veces, como en estos casos, se tiene la inevitable impresión de que el autor del Alexandre guardase en su memoria versos del Cantar, listos para ser reactualizados en su propia obra.

Ahora bien, no todas las filiaciones temáticas se originan necesariamente entre Alejandro y el Cid; también surgen entre este último y Darío. Ante una grave situación que los acongoja, ambos entienden las dificultades como enviadas por Dios y las agradecen:

$1440 \mathrm{C}$ Dario con la rencura dava grandes sospiros

1441c començó de fablar con los ojos mudados

$1442 \mathrm{a}$ «amigos»-diz-, «devémoslo a los dios gradeçer

Al inicio del Cantar, cuando el Cid sale desterrado camino de Burgos, se lee:

Sospiró mio Cid, ca mucho avié grandes cuidados,

fabló mio Cid, bien e tan mesurado:

- ¡Grado a ti, Señor, Padre que estás en lo alto! (6-8)

Las situaciones que escenifican Darío y el Cid coinciden en que ambos, primero, suspiran y, después, emiten unas emotivas palabras agradeciendo a Dios.

\subsection{Los sentidos: mirar y sentir}

Además del famosísimo verso 20, el primero que se conserva del Cantar de mio Cid es no sólo uno de los más conocidos, sino también uno de los más bellos: «de los sos ojos tan fuertemientre llorando». En términos retóricos se trata de la única ocasión en que se utiliza un hipérbaton en conjunto con esa expresión. En el resto de los casos, la frase se encuentra siempre en el primer hemistiquio salvo una vez: 
265 llorava de los ojos, quísol' besar las manos

$277 \quad$ llora de los ojos, tan fuertemientre sospira

$370 \quad$ llorando de los ojos, que non sabe qué se far

$374 \quad$ llorando de los ojos, que non viestes atal

1600 del gozo que avién de los sos ojos lloravan

En el Alexandre, la frase es menos común y sólo se usa para expresar tristeza y no alegría como en el verso 1600 del Cantar. De cualquier modo, no deja de sorprender su aparición en el texto del clérigo:

$401 \mathrm{~b} \quad$ llorando de los ojos díxole su rencura

1777a llorando de los ojos, començó de plañer

En realidad, existe toda una familia de equivalencias en base a las palabras ojo $\mathrm{u}$ ojos. Por ejemplo, la frase alçó los ojos consta en las dos obras. En el verso 588b del Alexandre se lee: «Ayaz alçó los ojos, vío quel querié dar». Esta expresión se encuentra en, por lo menos, 38 ocasiones en los manuscritos $\mathrm{O}$ y $\mathrm{P}$ combinados (Sas, 1976: 440). En el Cid aparece un par de veces:

1645 alçavan los ojos, tiendas vieron fincar

2439 alçó los ojos, estava adelant catando

También la frase $a$ ojo se registra en ambos poemas:

Alexandre:

67a quando tus enemigos a ojo los ovieres

1297a ya se veyén a ojo anbos los enperantes ${ }^{11}$

Cid:

1614 e del otra parte a ojo han el mar

1838 a ojo los avién los del que en buen ora nasco

2016 don lo ovo a ojo el que en buen ora nació

3024 cuando l'ovo a ojo el buen rey don Alfonso

11 Conviene señalar una discrepancia entre los dos manuscritos concerniente a las frases a ojo y por ojo. En la edición de Cañas, que sigue básicamente el manuscrito $\mathrm{P}$, el verso 2469a reza: «Ant que a Babilonia por ojo la veamos». Sin embargo, en el manuscrito O se lee: «Ante que a Babilonia a ojo la veamos» (Sas, 1976: 440). 
Una última reminiscencia en contexto similar se origina con las frases ver con los ojos o ver por los ojos:

Cid:

1683 él se lo vio con los ojos, cuéntangelo delant

2186 muchos días vos veamos con los ojos de las caras

Alexandre:

$713 \mathrm{C}$ veyéndolo por ojo toda su hermandat

$835 \mathrm{~d}$ por ojo lo vemos que somos aojados

1416a ya lo veyépor ojo com' avié a seer

2469a ant que a Babilonia por ojo la veamos

De manera similar acaece con el verbo plazer y los sintagmas en combinación con éste. Así, cuando ambos textos relatan la alegría que sienten los caudillos, utilizan la frase plogóa:

269a plogó a Alexandre con esta alegría

956a muchol plogó a Dario e mandó cavalgar

304 plogo a mio Cid, porque creció en la yantar

945 plogo a mio Cid e mucho a Álbar Fáñez

Pero no sólo se alegran los caudillos individualmente, sino también sus hombres son partícipes de su júbilo. En el verso 473a del Alexandre se dice: «a todos plogó mucho con esta abenençia». Y en el verso 305 del Cantar: «plogo a los otros omnes, todos cuantos con él están». En otros momentos la filiación surge debido a una actitud similar del Cid y de Alejandro. Los dos se alegran e inmediatamente se dirigen a Dios:

1157 alegre era el Cid e todas sus compañas,

1158 que Dios le ayudara e fiziera esta arrancada

295a alegrefue el rey quando fue arribado,

295b rendía a Dios gracias que l'avié aliñado 
También el verbo plazer puede combinarse con de coraçon para formar un nuevo sintagma:

$$
\begin{aligned}
& 1455 \text { Plógol' de coraçon e tornós' a alegrar } \\
& 2648 \text { el moro, cuando lo sopo, plógol' de coraçon } \\
& 3019 \text { cuando lo oyó el rey, plógol' de coraçon }
\end{aligned}
$$

68d sepas que a los tuyos plazrá de coraçon

Se observa otra vez que la reminiscencia no requiere ser idéntica para evocar en el lector del Alexandre un eco del Cid; asimismo se confirma que en las dos obras se mira y se siente de una manera equivalente.

\subsection{Vencedores y vencidos}

Cuando el Cid entra en Valencia, queda impresionado por el porte de los caballos y los vestidos de colores de sus habitantes:

Dentro en Valencia mio Cid el Campeador non lo detarda, pora las vistas se adobó: ¡tanta gruessa mula e tanto palafré de sazón tanta buena arma e tanto buen cavallo corredor, tanta buena capa e mantos e pelliçones!

Chicos e grandes vestidos son de colores. (1985-1990)

En el Alexandre se describen las riquezas y los habitantes de Babilonia con palabras análogas:

Las gentes son de preçio, mayores e menores,

todos andan vestidos de paños de colores cavalgan palafrenes e mulas ambladores los pobres omnes visten xamit' e çisclatones. (1500) Ambos poemas resaltan la vestimenta de color y la fuerza de los caballos y las mulas.

Otra imagen compartida es la colocación de la insignia militar propia en lo alto de la ciudad enemiga. Al conquistar Alejandro la ciudad de Uxión, se 
lee: «ovo en lo más alto el pendón a poner» (1579d). En el Cantar existen dos momentos equivalentes. Uno durante la toma del castillo de Alcocer y otro después de la conquista de Valencia:

611 vino Pero Vermúez, que la seña tiene en su mano,

612 metióla en somo, en todo lo más alto

1220 alegre era el Campeador con todos los que ha,

1221 cuando su señal cabdal sedié en somo del alcácer

A pesar de resultar siempre victoriosos, Alejandro y el Cid conocen la generosidad con los vencidos. Cuando el primero decide alejarse de tierras persas para continuar su incesante marcha hacia la India, los persas reconocen en él a un rey clemente y leemos que parte de tierras «onde ganó de todos los pueblos bendiçión» (1949b). De manera similar, en los momentos en que el Cid abandona Castejón y Alcocer respectivamente los habitantes moros lo bendicen, reconociendo en él un buen señor:

$541 \quad$ los moros e las moras bendiziéndol' están

$853-$-¡Vaste, mio Cid; nuestras oraciones váyante delante!

\subsection{Huestes y vasallos}

La lealtad, e incluso amor, que sus respectivas huestes muestran por sus caudillos, es una evidencia más de la influencia del Cid sobre el texto del clérigo:

Alexandre:

2283 b en dichos e en fechos que de cor me amades

$2295 \mathrm{C}$ «Señor»-dixeron todos-, «piensa de cavalgar,

2295 d todos te seguiremos por tierra e por mar».

Los versos ilustran la confianza que tienen sus hombres en Alejandro. Lo aman y están dispuestos a seguirlo literalmente hasta el fin del mundo. El caso del Cid es muy parecido. Sus hombres le obedecen ciegamente:

vassallos tan buenos por coraçón lo an,

mandado de so señor todo lo ban a far.

Ante que anochesca, piensan de cavalgar (430-432) 
No deja de sorprender que la ascendencia del cantar de gesta sea tan determinante sobre el Alexandre que su autor recurra a un «Señor, [...] piensa de cavalgar» para mostrar la determinación de los soldados de Alejandro, siendo este verso casi idéntico al 432 del Cid.

La relación entre vasallo y señor es uno de los temas centrales del Cantar:

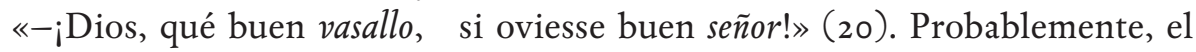
autor del Alexandre tuviera ese verso en mente cuando escribió: «vasallos sin señor sábense mal guardar» (893d). Y cuando en el Cid se enfatiza la fidelidad de los vasallos: «-¡Venides, Martín Antolínez, el mio fiel vasallo!» (204), el Alexandre se pone a coro con el verso: «quando tales vasallos tan leales me dieron» (946c).

\subsection{El viaje y ecos varios}

Retomar el camino es un motivo constante. Antes de emprender un nuevo viaje, Alejandro se encomienda a Dios: «antes quiso a Dios una oraçión fer» (120c). Inmediatamente después de su oración, el rey sale a galope: «cavalgó su cavallo e salió al trebejo» (125a). Estos dos versos tienen su probable origen en uno del Cantar. Después de enterarse en Burgos por una niña de nueve años de la disposición real en su contra, el Cid se dirige a Santa María, la catedral, para hacer una oración y salir, más tarde, cabalgando de la ciudad: «la oración fecha, luego cavalgava» (54).

Se concluye este apartado con varias reminiscencias cuya similitud es tan evidente que no ameritan mayor comentario:

Alejandro y el Cid pasan revista a sus respectivos ejércitos:

76a paró el rey sus hazes como costumbre era

417 mandó ver sus yentes mio Cid el Campeador

Orden de ataque:

$597-¡$ ¡Firidlos, cavalleros, todos sines dubdança!

1042d Feridlos, cavalleros, ca avedes rancado

Caballos sin jinetes:

997 por uno que firgades tres siellas irán vazias

$1389 \mathrm{~b}$ andavan con las siellas vazíos los cavallos 
Arrodillarse para hacer una oración:

2199b fincavan los ynojos, prometién oblaçiones

53 fincó los inojos, de coraçón rogava

En conclusión, la relación de dependencia que existe entre el Cantar y el Alexandre ha quedado ampliamente documentada, al establecerse el catálogo más extenso de equivalencias con el que se cuenta hasta el día de hoy. Si la poesía juglaresca sirvió "de modelo e iniciación a los clérigos que comenzaron a escribir en lengua vulgar" (1991: 355), según afirma Menéndez Pidal, también se puede ahora aseverar que, debido a la gran cantidad de reminiscencias identificadas entre el Alexandre y el Cid, este último debió de haber gozado de una especial difusión y de una considerable predilección en el autor del Libro de Alexandre, pese a la existencia de otros cantares. Del Cid toma el Alexandre técnicas narrativas, frases, conceptos retóricos y temáticos e imágenes, confirmándose de manera contundente «la falacidad de la escisión radical entre juglaría y clerecía» (Cañas, 1998: 52). Finalmente, se ha llegado al punto en que debemos dejar de percibir en el creador del Libro de Alexandre un autor «ajuglarado» y podemos empezar a llamarle, con todo derecho, un autor «cidiano».

\section{Bibliografía}

Cantar de mio Cid (1998): Alberto Montaner (ed.). Barcelona: Crítica.

Cañas, J. (1998): «Introducción». En: Jesús Cañas (ed.), Libro de Alexandre. Madrid: Cátedra, 11-82.

Libro de Alexandre (1998): Jesús Cañas (ed.). Madrid: Cátedra.

López Estrada, F. (1978): «Mester de clerecía: las palabras y el concepto». En: Journal of Hispanic Pbilology, 3, 165-174.

Menéndez Pidal, R. (1945): Cantar de mio Cid. Vocabulario. Madrid: EspasaCalpe.

Menéndez Pidal, R. (1991): Poesía juglaresca y juglares. Orígenes de las literaturas románicas. Madrid: Espasa-Calpe.

Menéndez Pelayo, M. (1944-1945): Antología de poetas líricos castellanos. Santander: Aldus.

Michael, I. (1961): «A Comparison of the Use of Epic Epithets in the Poema de mio Cid and the Libro de Alexandre». En: Bulletin of Hispanic Studies, $38,32-41$. 
Michael, I. (1970): The Treatment of Classical Material in the Libro de Alexandre. Manchester: Manchester UP.

Montaner, A. (1998): «Prólogo». En: Alberto Montaner (ed.), Cantar de mio Cid. Barcelona:

Crítica, 3-97.

Nelson, D. A. (1976): «Nunca devriés nacer': clave de la creatividad de Berceo». En: Boletín de la Real Academia Española, 56, 23-82.

Sas, L. F. (1976): Vocabulario del Libro de Alexandre. Madrid: Academia Española.

Smith, C. (1980): «Sobre la difusión del Poema de mio Cid». En: Jean Marie d'Heur y Nicoletta Cherubini (eds.), Études de philologie romane e d'bistoire littéraire offertes à Jules Horrent à l'occasion de son soixantième anniversaire. Liège, 417-427.

Willis, R. S. (1957): «'Mester de clerecía': A Definition of the Libro de Alexandre». En: Romance Pbilology, 3, 212-224. 
Francisco Ramírez Santacruz

Benemérita Universidad Autónoma de Puebla

\section{Jongleurs, authors and Mester de Clerecía. Similar topics and discursive strategies in Cantar de mio Cid and Libro de Alexandre}

Keywords: Cantar de mio Cid, Libro de Alexandre, Influence, Rhetoric, jongleur-like set of poetic habits

While many critics (Ramón Menéndez Pidal, Ian Michael and Colin Smith, among others) have suggested a likely influence of Cantar de mio Cid on the author of Libro de Alexandre, until now no comprehensive catalogue of concordances has been prepared in order to corroborate this hypothesis. This paper aims to provide the most extensive series of equivalences between these two works. A detailed three stage analysis of the poems reveals strong connections of both a thematic and formal nature. First, the common binomial expressions and similar phraseology in both texts are studied from a rhetorical point of view. Second, the constant dialogue with the listener - which both works share - represents a similarity of technique, that should not be underestimated. Third and finally, the analogous treatment that both poems give to certain themes (the spoils of war, the function of dreams, the relationship between conquerors and conquered, and the hero's journey) also reveals an extensive inventory of similarities. This study also confirms that a certain set of poetic habits identified by critics in Libro de Alexandre as a trait common to jongleurs is a direct legacy of the $\mathrm{Cid}$, which implies a wide distribution and popularity of the epic poem amongst the clergy. Finally, the results of this comparative analysis show a more intense relationship between the poetics of Spanish epic poetry and mester de clerecía than has been generally acknowledged. 
Francisco Ramírez Santacruz

Benemérita Universidad Autónoma de Puebla

\section{Potujoči pevci-avtorji v Mester de Clerecía. Retorične in vsebinske povezave med Cantar de mio Cid in Libro de Alexandre}

Ključne besede: Cantar de mio Cid, Libro de Alexandre, vplivi, retorika, navade potujočih pevcev

Čeprav številni kritiki že dlje časa predpostavljajo, da je Cantar de mio Cid najverjetneje vplival na avtorja Libro de Alexandre, doslej še nimamo poglobljenega popisa sovpadanj, ki bi potrjevala to hipotezo. Pričujoče delo poskuša zapolniti to vrzel in predstaviti kar najobsežnejši nabor vzporednic med deloma. Študija treh ravni (retorika, pripovedna tehnika in vsebina) ponudi neizpodbitne povezave tako idejne kot formalne narave. Poleg tega potrjuje, da so navade potujočih pevcev, ki jih je kritika dognala na podlagi Libro de Alexandre, neposredna dediščina Cida, kar pomeni, da se je junaški ep od nekdaj širil in bil priljubljen tudi pri duhovščini tistega časa. Nenazadnje pa izsledki primerjalne analize pričajo o še tesnejši povezanosti med poetiko španske epike in "mester de clerecía", kot je veljalo doslej. 